\title{
ABO Blood Group Alleles and Prostate Cancer Risk: Results from the Breast and Prostate Cancer Cohort Consortium (BPC3)
}

Sarah C. Markt, ${ }^{1 *}$ Irene M. Shui, ${ }^{1,2}$ Robert H. Unger, ${ }^{1}$ Yuksel Urun, ${ }^{3}$ Christine D. Berg, ${ }_{1}^{4}$ Amanda Black, ${ }^{5}$ Paul Brennan, ${ }^{6}$ H. Bas Bueno-de-Mesquita, $, 8,8,90$ Susan M. Gapstur, ${ }^{11}$ Edward Giovannucci, ${ }^{1,12}$ Christopher Haiman, ${ }^{13}$ Brian Henderson, ${ }^{13}$ Robert N. Hoover, ${ }^{6}$ David J. Hunter, ${ }^{1,2,14}$ Timothy J. Key, ${ }^{15}$ Kay-Tee Khaw, ${ }^{16}$ Federico Canzian, ${ }^{17}$ Nerea Larranga ${ }_{1}^{18,19}$ Loic Le Marchand, ${ }^{20}$ Jing Ma, ${ }^{1,21}$ Alessio Naccarati, ${ }^{22}$ Afshan Siddiq, ${ }^{23}$ Meir J. Stampfer ${ }^{1,21}$ Par Stattin, ${ }^{24}$ Victoria L. Stevens, ${ }^{12}$ Daniel O. Stram ${ }^{13}$ Anne Tjønneland, ${ }^{25}$ Ruth C. Travis, ${ }^{15}$ Dimitrios Trichopoulos, ${ }^{1,26,27}$ Regina G. Ziegler, ${ }^{6}$ Sara Lindstrom, ${ }_{1}^{1,14}$ Peter Kraft, ${ }^{1,14}$ Lorelei A. Mucci, ${ }^{1,21}$ Toni K. Choueiri, ${ }^{28}$ and Kathryn M. Wilson ${ }^{1}$

'Department of Epidemiology, Harvard T. H. Chan School of Public Health, Boston, Massachusetts

${ }^{2}$ Division of Public Health Sciences, Fred Hutchinson Cancer Research Center, Seattle, Washington

${ }^{3}$ Department of Medical Oncology, Ankara University Faculty of Medicine, Ankara, Turkey

${ }^{4}$ Department of Radiation Oncology, Johns Hopkins Medicine, Baltimore, Maryland

${ }^{5}$ Division of Cancer Epidemiology and Genetics, National Cancer Institute, Bethesda, Maryland

${ }^{6}$ International Agency for Research on Cancer, Lyon, France

${ }^{7}$ National Institute for Public Health and the Environment (RIVM), Bilthoven, the Netherlands ${ }^{8}$ Departments of Gastroenterology and Hepatology, University Medical Centre, Utrecht, the Netherlands ${ }^{9}$ Departments of Epidemiology and Biostatistics, The School of Public Health, Imperial College London, London, UK

${ }^{10}$ Departments of Social and Preventive Medicine, Faculty of Medicine, University of Malaya, Kuala Lumpur, Malaysia

"'Epidemiology Research Program, American Cancer Society, Atlanta, Georgia

Grant sponsor: US National Institutes of Health, National Cancer Institute; Grant numbers: U01-CA98233 (PHS, HPFS); U01-CA98710 (CPS2); U01-CA98216 (EPIC); U01-CA98758; R01 CA63464; P01 CA33619; R37 CA54281; UM1 CA164973 (MEC); Grant sponsor: Intramural Research Program of the Division of Cancer Epidemiology and Cancer Prevention (PLCO and ATBC); Grant sponsor: Division of Cancer Epidemiology and Genetics; Grant sponsor: Danish Cancer (Danish study Diet, Cancer and Health); Grant sponsor: Cancer Research EPIC study of vitamin $\mathrm{D}$ and prostate cancer and the EPIC-UK cohorts; Grant sponsor: Medical Research Council (EPIC study of vitamin D and prostate cancer and the EPIC-UK cohorts); Grant sponsor: (EPIC-Greece) Foundation; Grant sponsor: Health Research Fund (EPIC-Spain); Grant sponsor: Regional Governments of Andalucía, Asturias, Basque Country, Murcia (No. 6236) and Navarra (EPIC-Spain); Grant sponsor: ISCIII (EPIC-Spain); Grant number: RD06/0020; Grant sponsor: Sicilian government, Aire-Onlus Ragusa (Italy)(EPIC-Italy); Grant sponsor: European Commission (MORGEN-EPIC); Grant sponsor: International Agency for Research on (MORGEN-EPIC); Grant sponsor: Dutch Ministry of Public (MORGEN-EPIC); Grant sponsor: Welfare and Sports (MORGEN-EPIC); Grant sponsor: Statistics (MORGEN-EPIC); Grant sponsor: National Cancer Institute at the National Institutes of Health Training Grant; Grant number: (to SCM); Grant sponsor: U.S. Army Department of Defense Prostate Cancer Post-doctoral Fellowship; Grant number: (to IMS); Grant sponsor: Prostate Cancer Foundation Young Investigators; Grant number: (to LAM and KMW).

Toni K. Choueiri and Kathryn M. Wilson share last-authorship.

The authors report no conflicts of interests relating to this study.

*Correspondence to: Sarah C. Markt, Department of Epidemiology, Harvard T. H. Chan School of Public Health, 677 Huntington Avenue room 920A, Boston, MA 02115-6018. E-mail: sec110@mail.harvard.edu

Received 3 April 2015; Accepted 22 May 2015

DOI 10.1002/pros.23035

Published online 13 August 2015 in Wiley Online Library

(wileyonlinelibrary.com). 
${ }^{12}$ Department of Nutrition, Harvard T. H. Chan School of Public Health, Boston, Massachusetts

${ }^{13}$ Department of Preventive Medicine, Keck School of Medicine, University of Southern California, Los Angeles, California

${ }^{14}$ Program in Genetic Epidemiology and Statistical Genetics, Harvard T.H. Chan School of Public Health, Boston, Massachusetts

${ }^{15}$ Cancer Epidemiology Unit, Nuffield Department of Population Health, University of Oxford, Oxford, UK ${ }^{16}$ School of Clinical Medicine, Cambridge Institute of Public Health, University of Cambridge, Cambridge, UK

${ }^{17}$ Genomic Epidemiology Group, German Cancer Research Center (DKFZ), Heidelberg, Germany

${ }^{18}$ Public Health Division of Gipuzkoa, BIODonostia Research Institute, Basque Health Department, Spain

${ }^{19}$ CIBER of Epidemiology and Public Health (CIBERESP), Madrid, Spain

${ }^{20}$ Epidemiology Program, University of Hawaii Cancer Center, Honolulu, Hawaii

${ }^{2}$ 'Channing Division of Network Medicine, Brigham and Women's Hospital and Harvard Medical School, Boston, Massachusetts

${ }^{22} \mathrm{HuGeF}$ Foundation Molecular and Genetic Epidemiology Unit, Torino, Italy

${ }^{23}$ Department of Genomics of Common Disease, School of Public Health, Imperial College London, London, UK

${ }^{24}$ Department of Surgery and Perioperative sciences, Urology and Andrology, Umeå University, Sweden

${ }^{25}$ Danish Cancer Society Research Center, Copenhagen, Denmark

${ }^{26}$ Bureau of Epidemiologic Research, Academy of Athens, Athens, Greece

${ }^{27}$ Hellenic Health Foundation, Athens, Greece

${ }^{28}$ Department of Genitourinary Oncology, Dana Farber Cancer Institute, Boston, Massachusetts

\begin{abstract}
BACKGROUND. ABO blood group has been associated with risk of cancers of the pancreas, stomach, ovary, kidney, and skin, but has not been evaluated in relation to risk of aggressive prostate cancer.

METHODS. We used three single nucleotide polymorphisms (SNPs) (rs8176746, rs505922, and rs8176704) to determine ABO genotype in 2,774 aggressive prostate cancer cases and 4,443 controls from the Breast and Prostate Cancer Cohort Consortium (BPC3). Unconditional logistic regression was used to calculate age and study-adjusted odds ratios and $95 \%$ confidence intervals for the association between blood type, genotype, and risk of aggressive prostate cancer (Gleason score $\geq 8$ or locally advanced/metastatic disease (stage T3/T4/N1/M1).

RESULTS. We found no association between $\mathrm{ABO}$ blood type and risk of aggressive prostate cancer (Type A: $\mathrm{OR}=0.97,95 \% \mathrm{CI}=0.87-1.08$; Type $\mathrm{B}: \mathrm{OR}=0.92,95 \% \mathrm{CI}=\mathrm{n} 0.77-1.09$; Type $\mathrm{AB}: \mathrm{OR}=1.25,95 \% \mathrm{CI}=0.98-1.59$, compared to Type $\mathrm{O}$, respectively). Similarly, there was no association between "dose" of A or B alleles and aggressive prostate cancer risk.

CONCLUSIONS. ABO blood type was not associated with risk of aggressive prostate cancer. Prostate 75:1677-1681, 2015. ㅇ 2015 Wiley Periodicals, Inc.
\end{abstract}

KEY WORDS: $\quad$ ABO; blood type; prostate cancer; genetic epidemiology

\section{INTRODUCTION}

Blood group can be traced to a single gene, $A B O$, located on chromosome $9 \mathrm{q} 34$. $A B O$ encodes a glycosyltransferase that catalyzes the transfer of carbohydrates to red blood cells, thereby forming the distinct antigenic structures of the A and B blood groups. $\mathrm{ABO}$ blood group has been associated with several malignancies, including cancers of the pancreas [1], ovary [2], kidney [3], and skin [4]. One study failed to show an association between $\mathrm{ABO}$ blood group and overall prostate cancer [5]; however, no studies have focused on aggressive prostate cancer, which have been shown to be etiologically different from indolent cancer [6]. We used genotype data to investigate the association between $\mathrm{ABO}$ blood type $(\mathrm{A}, \mathrm{B}, \mathrm{AB}$, and $\mathrm{O})$, as well as variation in $\mathrm{ABO}(\mathrm{OO}, \mathrm{AO}, \mathrm{AA}, \mathrm{AB}, \mathrm{BO}$, and $\mathrm{BB})$ and aggressive prostate cancer risk.

\section{MATERIALS AND METHODS}

Data were from the Breast and Prostate Cancer Cohort Consortium (BPC3) aggressive prostate cancer 
genome-wide association study (GWAS), described in detail elsewhere [7]. Cases and controls were selected from prospective cohort studies, and were restricted to men of European ancestry. Cases were men with incident prostate cancer with high-histologic grade (Gleason score $\geq 8$ ) or locally advanced/metastatic disease (stage T3/T4/N1/M1); cases were followed for overall and cancer-specific mortality. Controls were men without a diagnosis of prostate cancer. Assessment of $\mathrm{ABO}$ blood group alleles was conducted using genotype data from rs505922, rs8176704, and rs8176746 in $\mathrm{ABO}$ to infer-phased haplotypes for each participant with $>99 \%$ posterior probability, based on an expectation-maximization algorithm [8], similarly to prior studies [1,2]. Briefly, rs8176746 is a marker of the B allele and rs505922 is a proxy $\left(r^{2}=1\right)$ for rs687289, a marker of the $\mathrm{O}$ allele; rs8176704 distinguishes the $\mathrm{A}^{1}$ and $\mathrm{A}^{2}$ alleles [8]. Unconditional logistic regression estimated odds ratios (ORs) and $95 \%$ confidence intervals ( $95 \% \mathrm{CIs}$ ) of the association between $\mathrm{ABO}$ blood group and aggressive prostate cancer adjusted for age and study. We further examined dose of $\mathrm{A}$ and $\mathrm{B}$ alleles by investigating the association between risk of aggressive prostate cancer and $\mathrm{ABO}$ genotype $(\mathrm{AO}, \mathrm{AA}, \mathrm{BO}, \mathrm{BB}, \mathrm{AB}$, and $\mathrm{OO})$. We also examined study-specific associations between $\mathrm{ABO}$ blood group and aggressive prostate cancer. Among cases, we used Cox proportional hazards regression to assess the association between $\mathrm{ABO}$ blood group and prostate cancer-specific mortality, adjusted for age at diagnosis and study. $P$ values were two sided and analyses were done using SAS statistical packages (SAS Institute).

\section{RESULTS}

The study included 2,774 aggressive prostate cancer cases and 4,443 controls. The frequency of $\mathrm{ABO}$ blood group is shown in Table I and for each cohort in Supplemental Table SI. When adjusted for age and study, there was no association between $\mathrm{ABO}$ blood types and risk of aggressive prostate cancer (Table I). We found no association between Type $A$ or $A B$, compared to Type $\mathrm{O}$, and risk of aggressive disease.
Similar results were observed when we evaluated $A B O$ genotype (Supplemental Table SII). In the case-only analysis $(n=2,774)$, there was no association between $\mathrm{ABO}$ blood group or genotype and prostate cancer-specific mortality ( $\mathrm{n}=598$ prostate cancer deaths) (data not shown).

Figure 1 presents study-specific odds ratios for $\mathrm{ABO}$ blood group and risk of aggressive disease. There was heterogeneity across studies and no statistically significant associations comparing Type A or B to Type $\mathrm{O}$ in any individual study. There was a positive association with aggressive prostate cancer comparing Type $\mathrm{AB}$ to $\mathrm{O}$ in the Multiethnic Cohort $(\mathrm{OR}=3.34,95 \% \mathrm{CI}=1.01-11.03)$ and an inverse association in the Physicians' Health Study $(\mathrm{OR}=0.35,95 \%$ $\mathrm{CI}=0.15-0.86)$.

\section{DISCUSSION}

In this large nested case-control study, we found no significant association between $\mathrm{ABO}$ blood group and aggressive prostate cancer risk or prostate cancer-specific mortality. These data are consistent with a prior study examining prostate cancer risk overall [5].

Previous studies have generally shown an increased risk of cancer, including pancreas, ovarian, and renal, for non-Type $\mathrm{O}$ blood group compared to Type O [1-3]. The potential mechanisms linking ABO to risk of cancer are unclear. It has been suggested that $\mathrm{ABO}$ antigens interfere with intercellular adhesion and membrane signaling, and may be involved with angiogenesis [3]. In addition, ABO blood group may affect the systemic inflammatory state and immune surveillance for malignant cells $[1,3,4]$.

A strength of this study is the use of genotype-derived blood groups, which reduced the risk of exposure misclassification from self-report blood type and allowed us to specifically assess whether genotypic variation in $\mathrm{ABO}$ was associated with aggressive prostate cancer risk. Restricting to men of European ancestry may limit the generalizability of our findings to men of other ethnicities with differing prevalence of blood types and prostate cancer risk. Finally,

TABLE I. Odds Ratios (or) and 95\% Confidence Intervals ( $\mathrm{Cl}$ ) of the Association Between ABO Blood Type and Aggressive Prostate Cancer* Risk, Breast and Prostate Cancer Cohort Consortium

\begin{tabular}{lcccc}
\hline & Type O & Type A & Type B & Type AB \\
\hline N (\%) cases & $1172(42 \%)$ & $1182(43 \%)$ & $285(10 \%)$ & $135(5 \%)$ \\
N (\%) controls & $1772(40 \%)$ & $1928(44 \%)$ & $534(12 \%)$ & $209(5 \%)$ \\
Multivariable adjusted OR $(95 \% C I)^{a}$ & Ref. & $0.97(0.87-1.08)$ & $0.92(0.77-1.09)$ & $1.25(0.98-1.59)$ \\
\hline
\end{tabular}

*Aggressive prostate cancer defined as Gleason $8+$ or locally advanced/metastatic disease.

${ }^{a}$ Adjusted for age and study cohort. 


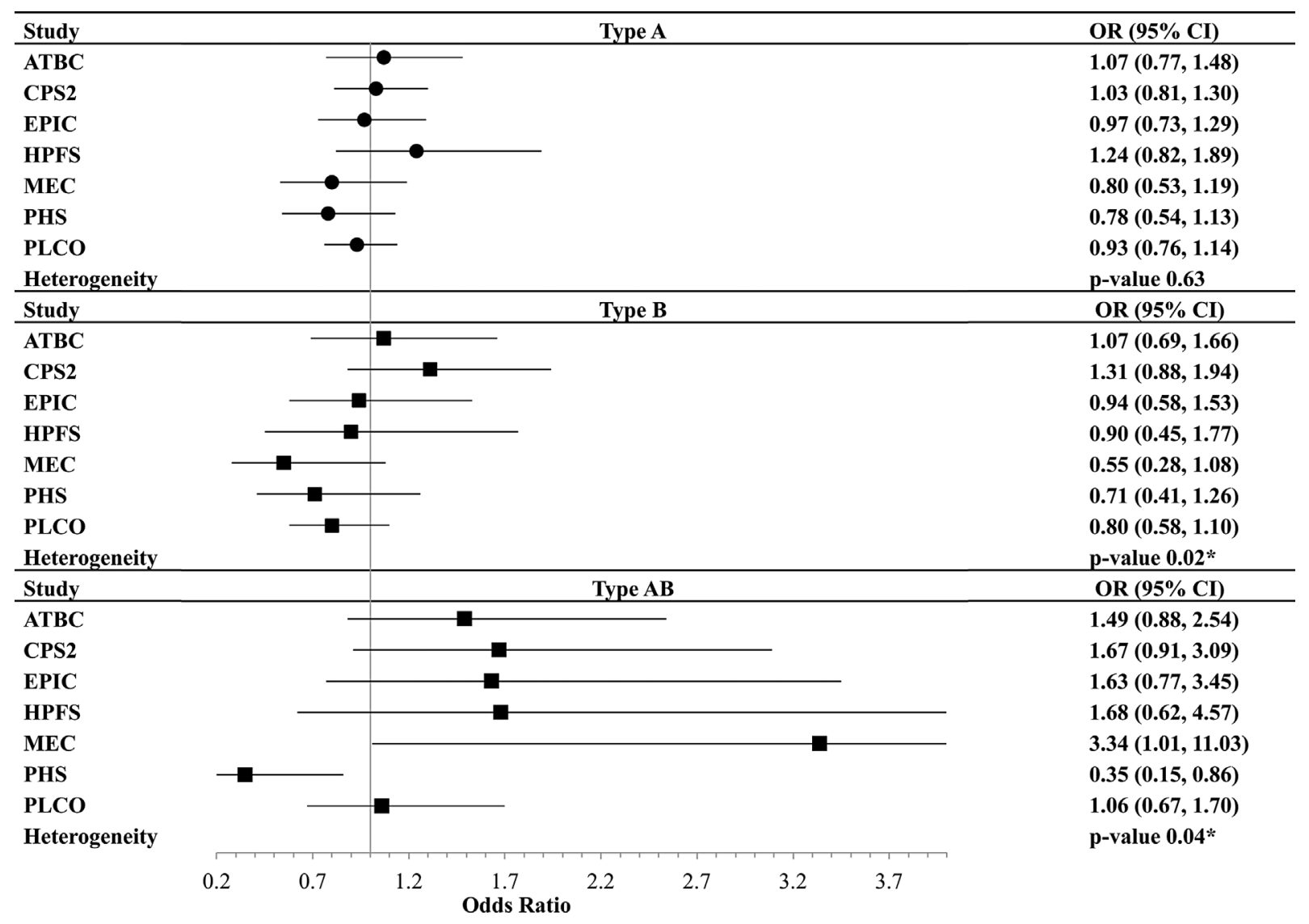

Fig. I. Association between $A B O$ blood type and aggressive prostate cancer risk by study, Breast and Prostate Cancer Cohort Consortium. *Heterogeneity across the cohort was assessed using P-value from Cochran's $Q$ statistic.

despite a large overall study, the prevalence of type $A B$ was low. Although there is some heterogeneity among studies, overall $\mathrm{ABO}$ blood type and $\mathrm{ABO}$ genotype do not appear to play a role in the development or progression of prostate cancer.

\section{ACKNOWLEDGMENTS}

The authors would like to thank all of the participants of the BPC3 studies. The authors thank Dr. Philip Prorok, Division of Cancer Prevention, NCI; the screening center investigators and staff of the PLCO Cancer Screening Trial; Mr. Thomas Riley and staff at Information Management Services, Inc.; and Ms. Barbara O'Brien and staff at Westat, Inc., for their contributions to the PLCO Cancer Screening Trial. We thank Hongyan Huang for assistance in preparing the data. The BPC3 is supported by the US National Institutes of Health, National Cancer Institute under cooperative agreements U01-CA98233 (PHS,HPFS), U01-CA98710 (CPS2), U01-CA98216 (EPIC), U01-CA98758, R01 CA63464, P01 CA33619, R37 CA54281, and UM1 CA164973 (MEC). PLCO and ATBC was supported by the Intramural Research Program of the Division of Cancer Epidemiology and Genetics and by contracts from the Division of Cancer Prevention, National Cancer Institute, NIH, DHHS. The Danish Study Diet, Cancer and Health was funded by the Danish Cancer Society. The EPIC study of vitamin D and prostate cancer and the EPIC-UK cohorts were supported by funding from Cancer Research UK and Medical Research Council UK. EPIC-Greece was supported through the Hellenic Health Foundation. EPIC-Spain was supported by Health Research Fund (FIS); Regional Governments of Andalucía, Asturias, Basque Country, Murcia (No. 6236) and Navarra; and ISCIII RETIC (RD06/0020) (Spain). EPIC-Italy was supported by the Sicilian government, Aire-Onlus Ragusa (Italy). MORGEN-EPIC was supported by the European Commission (DG-SANCO), the International Agency for Research on Cancer, the Dutch Ministry of Public Health, Welfare and Sports (VWS), and Statistics Netherlands. I. M. Shui received a US Army Department of Defense Prostate Cancer Post-Doctoral Fellowship. L. A. Mucci and K. M. Wilson are Prostate Cancer Foundation Young Investigators. S. C. Markt is 
supported by the National Cancer Institute at the National Institutes of Health Training Grant (T32 CA09001).

\section{REFERENCES}

1. Wolpin BM,Kraft P, Gross M, Helzlsouer K, Bueno-de-Mesquita HB, Steplowski E, Stolzenberg-Solomon RZ, Arslan AA, Jacobs EJ, Lacroix A, Petersen G, Zheng W, Albanes D, Allen NE, Amundadottir L, Anderson G, Boutron-Ruault MC, Buring JE, Canzian F, Chanock SJ, Clipp S, Gaziano JM, Giovannucci EL, Hallmans G, Hankinson SE, Hoover RN, Hunter DJ, Hutchinson A, Jacobs K, Kooperberg C, Lynch SM, Mendelsohn JB, Michaud DS, Overvad K, Patel AV, Rajkovic A, Sanchez MJ, Shu XO, Slimani N, Thomas G, Tobias GS, Trichopoulos D, Vineis $P$, Virtamo J, Wactawski-Wende J, Yu K, Zeleniuch-Jacquotte A, Hartge P, Fuchs CS. Pancreatic cancer risk and ABO blood group alleles: Results from the pancreatic cancer cohort consortium. Cancer Res 2010;70(3):1015-1023.

2. Gates MA, Wolpin BM, Cramer DW, Hankinson SE, Tworoger SS. ABO blood group and incidence of epithelial ovarian cancer. Int J Cancer 2011;128(2):482-486.

3. Joh HK, Cho E, Choueiri TK. ABO blood group and risk of renal cell cancer. Cancer Epidemiol 2012;36(6):528-532.

4. Xie J, Qureshi AA, Li Y, Han J. ABO blood group and incidence of skin cancer. PLoS One 2010;5(8)):e11972.

5. Iodice S, Maisonneuve P, Botteri E, Sandri MT, Lowenfels AB. $\mathrm{ABO}$ blood group and cancer. Eur J Cancer 2010;46(18): 3345-3350.
6. Giovannucci E, Liu Y, Platz EA, Stampfer MJ, Willett WC. Risk factors for prostate cancer incidence and progression in the health professionals follow-up study. Int J Cancer 2007;121(7):1571-1578.

7. Schumacher FR, Berndt SI, Siddiq A, Jacobs KB, Wang Z, Lindstrom S, Stevens VL, Chen C, Mondul AM, Travis RC, Stram DO, Eeles RA, Easton DF, Giles G, Hopper JL, Neal DE, Hamdy FC, Donovan JL, Muir K, Al Olama AA, Kote-Jarai Z, Guy M, Severi G, Gronberg H, Isaacs WB, Karlsson R, Wiklund F, Xu J, Allen NE, Andriole GL, Barricarte A, Boeing H, Bueno-de-Mesquita HB, Crawford ED, Diver WR, Gonzalez CA, Gaziano JM, Giovannucci EL, Johansson M, Le Marchand L, Ma J, Sieri S, Stattin P, Stampfer MJ, Tjonneland A, Vineis P, Virtamo J, Vogel U, Weinstein SJ, Yeager M, Thun MJ, Kolonel LN, Henderson BE, Albanes D, Hayes RB, Feigelson HS, Riboli E, Hunter DJ, Chanock SJ, Haiman CA, Kraft P. Genome-wide association study identifies new prostate cancer susceptibility loci. Hum Mol Genet 2011;20(19):3867-3875.

8. Kraft P, Cox DG, Paynter RA, Hunter D, De Vivo I. Accounting for haplotype uncertainty in matched association studies: A comparison of simple and flexible techniques. Genet Epidemiol 2005;28(3):261-272.

\section{SUPPORTING INFORMATION}

Additional supporting information may be found in the online version of this article at the publisher's web-site. 